\title{
Tissue scurvy misdiagnosed as shaken baby syndrome homicide
}

\author{
Michael D. Innis \\ Retired Haematologist Princess Alexandra Hospital Brisbane Australia
}

Email address

micinnis@bigpond.com

\section{To cite this article:}

Michael D. Innis. Tissue Scurvy Misdiagnosed as Shaken Baby Syndrome Homicide. Clinical Medicine Research. Vol. 3, No. 1, 2014, pp. 6-8. doi: 10.11648/j.cmr.20140301.12

\begin{abstract}
Tissue Scurvy" is an autoimmune disorder in which there is an abundance of Vitamin C in the body(unlike the Seafarer Scurvy of yesteryear) but it is inhibited from entering the tissue cells to perform its functions of maintaining the integrity of the blood vessels and skeletal tissue and partaking in several enzymatic reactions because of the lack of insulin which is essential for the transfer of Vitamin $\mathrm{C}$ into the cell. The result is the development of fractures, hemorrhages and other lesions of Scurvy. Here it is shown a child alleged to have been murdered by being shaken to death was found to have hyperglycemia, implying insulin deficiency and concomitant Tissue Scurvy. It is concluded that the diagnosis Shaken Baby Syndrome, and all examples of unexplained fractures, bruises, retinal and subdural hemorrhages with encephalopathy - the so-called "TRIAD" - are in fact an autoimmune disorder following antigenic stimulation in a genetically susceptible child. Vaccines administered within 4 weeks of the onset of symptoms are the most common cause. The Shaken Baby Syndrome is a fabricated diagnosis and has no place in medical jurisprudence.
\end{abstract}

Keywords: Shaken Baby Syndrome, Tissue Scurvy, Homicide

\section{Introduction}

The late Dr Archie Kalokerinos was the first to point out that Tissue Scurvy was the cause of what doctors were calling Shaken Baby Syndrome. In his book, Every Second Child, he said, "during one trial the prosecution said scurvy was no longer seen, I replied- yes it is but it is not called scurvy it is called Shaken Baby Syndrome" [1]. By reducing or delaying immunization he was able to reduce the infant mortality in his practice.

A clue to the pathophysiology of Tissue Scurvy is provided by the fact that the blood glucose is invariably elevated and this can only happen when the level of insulin in the blood, essential for the transfer of Vitamin $\mathrm{C}$ into the cell, is reduced [2].

Normally insulin binds to its receptor on the cell surface and initiates a chain of events that leads to the insertion in the plasma membrane of a transmembrane glucose transporter called GLUT 4 which facilitates the transport of glucose and other nutrients into the cell. It is the failure of this process, because of the lack of Insulin, which prevents the entry of Vitamin $\mathrm{C}$ into the cell and causes "tissue scurvy."

Tissue scurvy, when it involves the cells of the liver, as shown by abnormal Liver Function Tests, leads to under carboxylation of the coagulation factors and osteocalcin resulting in bruises, hemorrhages and fractures [3].

This report concerns a child who was vaccinated with the MMR and other vaccines and developed autoimmune diabetes and associated Tissue Scurvy a week later which was misdiagnosed as Shaken Baby Syndrome and the carer found guilty of murder and incarcerated.

\section{Case History}

The child was born on the $9^{\text {th }}$ May 2011 by normal vaginal delivery following a 41 week gestation period. Her Apgar scores were 9 at 1 minute and 10 at 5 minutes and she weighed $3.3 \mathrm{~kg}$. She was given an injection of Vitamin K.

She was seen by the Health Visitor on $20^{\text {th }}$ May 2011 and was found to have an infected finger which healed by the next visit on $31^{\text {st }}$ May 2011. Her weight was $3310 \mathrm{gm}$

On $3^{\text {rd }}$ June 2011 she had an episode of difficulty in breathing and was examined in Accident and Emergency and the mother given advice but no form of medicinal therapy was administered. She received the first primary immunization of childhood on $8^{\text {th }}$ July 2011. 
In January 2012 she developed an ear infection and on $26^{\text {th }}$ March 2012 a bruise was noticed on the tip of the pinna of one ear. No Laboratory Investigations were done.

She was vaccinated with the MMR, Hib and Meningococcal $\mathrm{C}$ vaccines on the $23^{\text {rd }}$ May 2012 and a week later, on $1^{\text {st }}$ June 2012, she was taken to the Boston Pilgrim Hospital where a Consultant Pediatrician found a $5 \mathrm{~cm} \mathrm{X} 5 \mathrm{~cm}$ boggy bruise on her head, subconjunctival hemorrhages in the left eye and what was thought to be a "human bite mark" on the posterior aspect of the left leg. No neurological lesions were seen and there were no retinal hemorrhages.

Social workers and Police were informed and after a short stay in the home of the grandparents she was returned to her family and visited by her Health Visitor on the $26^{\text {th }}$ July 2012 who found no concerns. There is no record of any coagulation studies having been done inspite of the fact that a cephalo-hematoma (boggy swelling on the head) is a "herald lesion" anticipating the onset of a catastrophichemorrhagic disaster [4].

On the $28^{\text {th }}$ July 2012 shewas well for most of the day and at about $15.30 \mathrm{hrshad}$ a meal but vomited some watery fluid and the carer gave her a bath and she seemed normal. He dried her and placed her on the settee in the living room and left the room to get her a drink.

When he returned shortly afterwards he found she had fallen off the settee and was on the floor on her back unconscious and fitting. She arched her back and then became limp. He shook her about 6 times in an attempt to reviveher but was unsuccessful. He then laid her on the couch and smacked her back hoping to dislodge anything that may have stuck in her throat. His efforts to restore her normal breathing were unsuccessful and the Emergency Services were alerted and she was taken to the Dianna Princess of Wales Hospital Grimsby.

The epileptic seizure continued. A high Blood Sugar and a Metabolic Acidosis were noted and an examination of the Urine showed high amounts of Glucose and ketones and some blood --features of Tissue Scurvy [5]. No bruises were noted. Coagulation studies were done and showed a raised APTT 39.6.seconds, Prothrombin Time 15.0 seconds. Platelet count $697 \times 10^{9} / \mathrm{L}$, Ammonia $77 \mathrm{mmol} / / \mathrm{L}$ Liver Function Test results were not revealed in the information sent to me. She was transferred to the Intensive Care Unit of the Sheffield Children's Hospital where a review of the CT Scans and Ophthalmoscopy showed "changes consistent with evolving Hypoxic-Ischaemic Non-accidental Brain Injury".

Her condition continued to deteriorate and she died at $02.15 \mathrm{hrs}$ on the $1^{\text {st }}$ August 2012and a post-mortem examination was carried out.

\section{Post-Mortem Examination}

The essential lesions were swelling of the brain, retinal hemorrhages and detachment in both eyes. No external injuries were found.
The brain and spinal cord was said to show evidence of old and recent injury. The old injury was represented by the presence of a subdural hematoma over the brain and spinal cord of several weeks to months' duration and bilateral contusions in the parasagittal region of the posterior frontal lobe with some histological appearances consistent with several days to weeks' duration.

The recent head injury, it was claimed, was demonstrated by the presence of a recent hematoma over the brain and spinal cord with localized axonal injury to the cortico-spinal tracts of medulla and axonal injury to the spinal nerve roots.

There was generalized ischemia in the brain involving cortex white matter, deep grey matter, cerebellum, hypocampus and spinal cord.

The cause of death was attributed to "Shaken Baby Syndrome". The care giver was arrested, charged with murder, tried, convicted and imprisoned.

\section{Discussion}

Both Dr Archie Kalokerinos [6] and Professor Alan Clemetson [7] realized many years ago that what doctors were calling Shaken Baby Syndrome was in fact a manifestation of Infantile Scurvy. As stated above Dr Kalokerinos records his court encounter with a prosecutor at the trial of a mother accused of murder who claimed "Scurvy does not exist anymore" to which he replied. "yes it does but now you call it Shaken Baby Syndrome".

Relevant to the child's illness on June $2^{\text {nd }} 2012$ is the fact that she was vaccinated with the MMR, Hib and Meningococcal $\mathrm{C}$ vaccines on the $23^{\text {rd }}$ May 2012and a week later, on $1^{\text {st }}$ June 2012 she was taken to the Boston Pilgrim Hospital where a Consultant Pediatrician found a $5 \mathrm{~cm} \mathrm{X} 5 \mathrm{~cm}$ boggy bruise on her head, subconjunctival hemorrhages in the left eye and what was thought to be a human bite mark on the posterior aspect of left leg.

Coagulation studies were done and showed APTT 39.6.seconds, Prothrombin Time 15.0 seconds and Platelet count $697 \times 10^{9} / \mathrm{L}$. These results are decidedly abnormal when compared with the Normal ranges of the Children's Hospital at Great Ormond Street and they indicate the child has a Coagulation Disorder which would explain the hemorrhages and the "human bite".

Liver Function Test results, which are invariably abnormal in this condition were not done or if done have not been sent to me. With regard to treatment an immediate IM injection of Vitamin $\mathrm{K}$ and an IV injection of Vitamin $\mathrm{C}$ would have possibly reversed the process when the child presented at the Princess of Wales Hospital but it appears no such treatment was given in spite of the fact that the coagulation studies clearly indicated the need for such action.

The observation of two hematomas of different ages at the post-mortem can be explained by the fact that on March $26^{\text {th }} 2012$ a bruise was noticed on the tip of the pinna of one ear. This lesion is often the result of a nutritional deficiency of Vitamin C and it is highly probable that the earlier hematoma was another manifestation of the same process - 
Tissue Scurvy. This would also explain the radiological findings. No Laboratory Investigations were done when the bruise was noticed which is very unusual and an opportunity to treat the disorder was missed.

The suggestion that "the most likely explanation of the child's presentation is likely to have involved shaking" is a view which has been debunked. Nowhere in the enormous amount of literature on the subject of the Shaken Baby Syndrome [8-18] have the authors explained how shaking an infant can raise the level of the blood sugar or cause glucose to appear in the urine

These are not changes produced by shaking the child, they are proved to be the result of an Autoimmune Reaction following vaccination of a genetically susceptible child.

The results of tests for Liver Function have not been provided in the material sent to me. Truth withheld is Justice denied. These results will undoubtedly be abnormal because the Prothrombin Time of 15 seconds is outside the normal upper limit of 14.1 reported by Great Ormond Street Hospital. An APTT of 39.6 seconds is also evidence of a defective coagulation mechanism accounting for all the child's problems.

\section{Conclusion}

The accusation of Shaken Baby Syndrome is a misdiagnosis. The evidence proves an Autoimmune Reaction to vaccines administered on $23^{\text {rd }}$ May 2012was the cause of death. The diagnosis Shaken Baby Syndrome was suggested by a neurosurgeon without the slightest scientific evidence to support it and an innocent carer is in prison accused of Murder.

The remedy lies in educating doctors to recognize Tissue Scurvy

\section{Acknowledgements}

I wish to thank Mrs Elisabeth Peel for providing me with the information used in this report and my wife Beverley for editorial assistance. I discussed the subject with $\mathrm{Dr}$ Archie Kalokerinos and he and Professor Clemetson kindly sent me copies of their publications.

\section{References}

[1] Kalokerinos A. Every Second Child. 1981 pp 3-165 Thomas Nelson (Australia)
[2] Cunningham JJ. The Glucose/Insulin System and Vitamin C: Implications in Insulin-dependent Diabetes Mellitus. J Am CollNutr; 1998:vol 17 p105-108

[3] Cunningham JJ, Ellis SL, McVeigh KL, Levine RE, Jorge Calies Escandon Reduced mononuclear leucocyte ascorbic acid content in adults with insulin-dependent diabetes mellitus consuming adequate dietary vitamin $\mathrm{C}$ Metabolism 1981; vol 40;148-149.

[4] Innis MD. Vitamin K Deficiency Disease. Jour of Orthomol Med 2008; vol 23; 15-20

[5] Innis MDAutoimmune Tissue Scurvy Misdiagnosed as ChildAbuseClinical Medicine Research2013; 2(6): 154-157

[6] Clemetson CAB: Caffey Revisited: A Commentary n the Origin of "Shaken Baby Syndrome."J Am PhysSurg, 2006; 11: $20-21$.

[7] Caffey J: Multiple fractures in the long bones of infants suffering from chronic subdural hematoma. Am $J$ Roentgenol, 1946; 56: 163-173.

[8] GuthkelchAN: Infantile subdural haematoma and its relationship to whiplash injuries. $B M J, 1971$; ii: 430-1.

[9] Caffey J: The whiplash shaken infant syndrome: manual shaking by the extremities with whiplash-induced intracranial and intraocular bleedings, linked with residual permanent brain damage and mental retardation. Pediatrics, 1974; 54: 396-403.

[10] Joint statement on Shaken Baby Syndrome. Paediatrics \& Child Health2001; 6(9): 663-7.

[11] Duhaime AC: Christian CW, Rorke LB, etal.Non-accidental head injury in infants - theshaken baby syndrome. $N$ Engl $J$ Med 1998;338: 1822-1829.

[12] David TJ: Shaken baby (shaken impact) syndrome:nonaccidental injury in infancy. $J$ RSoc Med 1999; 92: 556-561.

[13] Editorial. Shaken Babies. Lancet 1998;352(9125): 335.

[14] Minns RA. Busuttil A: Patterns of presentation of the shaken baby syndrome Four types of inflicted brain injury predominate $B M J$ 2004;328: 766

[15] Harding B, Risdon RA, Krous HF: Shaken baby syndrome $B M J$, Mar 2004; 328: 720 - 721.

[16] Hoskote A, Richards P, Anslow P, McShaneT: Subdural haematoma and non-accidental injury in children. Child's NervSyst, 2002; 18:311-317

[17] Liesner, Hann I, Khair K: Non-accidental injury and the haematologist: the causes and investigation of easy bruising. Blood CoagulFibrinolysis15 (suppl 1): S41 -S48 2004 